\title{
CARACTERIZAÇÃO DE CINZA DO BAGAÇO DE CANA-DE-AÇÚCAR PARA EMPREGO COMO POZOLANA EM MATERIAIS CIMENTÍCIOS
}

\author{
Guilherme Chagas Cordeiro* \\ Laboratório de Engenharia Civil, Universidade Estadual do Norte Fluminense Darcy Ribeiro, Av. Alberto Lamego, 2000, \\ 28013-602 Campos dos Goytacazes - RJ, Brasil \\ Romildo Dias Toledo Filho e Eduardo de Moraes Rego Fairbairn \\ Instituto Alberto Luiz de Coimbra de Pós-graduação e Pesquisa de Engenharia, Universidade Federal do Rio de Janeiro, CP 68506, \\ 21941-972 Rio de Janeiro - RJ, Brasil
}

Recebido em 10/1/08; aceito em 23/7/08; publicado na web em 20/1/09

\begin{abstract}
CHARACTERIZATION OF SUGAR CANE BAGASSE ASH FOR USE AS POZZOLAN IN CEMENTITIOUS MATERIALS. This work presents the results of morphological and physical-chemical characteristics of a sugar cane bagasse ash material sample produced under controlled burning conditions. The investigation was carried out by analyzing chemical composition, X-ray diffraction, ${ }^{29} \mathrm{Si}$ nuclear magnetic resonance, morphology, thermal analysis, particle size, specific surface, and density. Moreover, the pozzolanic activity of the ash was evaluated by pozzolanic activity index and Chapelle's method. The results suggest that the sugar cane bagasse ash has adequate properties to be used as pozzolan in construction materials.
\end{abstract}

Keywords: sugar cane bagasse ash; pozzolan; characterization.

\section{INTRODUÇÃO}

Pozolana é o material inorgânico, natural ou artificial, silicoso ou alumino-silicoso, que pode apresentar propriedades aglomerantes quando finamente moído e em presença de água e hidróxido de cálcio. O emprego de pozolana como material cimentício remonta à antiguidade. Registros históricos indicam que, há cerca de 2000 anos, os romanos já utilizavam em suas construções uma cinza de origem vulcânica proveniente da localidade de Pozzuoli (antiga Puteoli do Império Romano), Itália, o que conferiu a denominação "pozolana" ao material. ${ }^{1}$

Atualmente, diversos materiais pozolânicos, como cinza volante, sílica ativa, metacaulim e cinza da casca de arroz, são utilizados em substituição parcial ao cimento Portland em pastas, argamassas e concretos. $^{2} \mathrm{O}$ emprego de pozolanas possibilita a redução de problemas ambientais relacionados ao uso de cimento Portland em concreto, como grande quantidade requerida de matéria-prima natural (argila e calcário) e elevado montante de gases intensificadores do efeito estufa, sobretudo dióxido de carbono, emitidos para a atmosfera durante sua produção.

A aplicação das pozolanas como substitutas parciais de cimento Portland deve-se à presença de fases ativas em sua constituição química. A sílica amorfa é a principal fase ativa das pozolanas e, em contato com água e à temperatura ambiente, solubiliza em meio alcalino e reage com íons $\mathrm{Ca}^{+2}$ para formar silicatos de cálcio hidratados $(\mathrm{C}-\mathrm{S}$ $\mathrm{H}$, de acordo com notação utilizada na química do cimento: C-CaO; $\mathrm{S}-\mathrm{SiO}_{2} ; \mathrm{H}_{-} \mathrm{H}_{2} \mathrm{O}$ ), conforme ilustra a Equação 1. O C-S-H formado nestas reações pozolânicas é similar ao $\mathrm{C}-\mathrm{S}$-H produzido nas reações de hidratação do cimento Portland. ${ }^{3} \mathrm{O}$ hidróxido de cálcio formado durante a hidratação do cimento Portland é a principal fonte de cálcio para as reações pozolânicas.

$x \mathrm{SiO}_{2}+y \mathrm{CaO}+z \mathrm{H}_{2} \mathrm{O} \rightarrow x \mathrm{CaO} \cdot y \mathrm{SiO}_{2} \cdot z \mathrm{H}_{2} \mathrm{O}$

\footnotetext{
*e-mail: gcc@uenf.br
}

A cinza proveniente da queima do bagaço de cana-de-açúcar apresenta como principal composto químico a sílica, normalmente em quantidade acima de $60 \%$ em massa. ${ }^{4}$ De acordo com as condições de queima adotadas, é possível manter a sílica contida no bagaço em estado amorfo. ${ }^{4}$ Essa característica pode possibilitar o emprego desse resíduo como pozolana e, por conseguinte, reduzir as despesas e o impacto ambiental relativos à sua disposição no meio ambiente. Além disso, a incorporação da cinza pode agregar valor econômico ao resíduo agroindustrial e proporcionar vantagens técnicas e ambientais com a substituição parcial de cimento Portland. É relevante destacar que o silício é absorvido do solo pelas raízes da cana-deaçúcar na forma de ácido monossilícico $\left(\mathrm{H}_{4} \mathrm{SiO}_{4}\right)$ e, após a saída de água da planta por transpiração, deposita-se na parede externa das células da epiderme como sílica gel. O acúmulo de sílica entre a cutícula e a parede das células da epiderme funciona como barreira física à penetração de fungos patogênicos e reduz a perda de água por transpiração. ${ }^{5}$

O Brasil é atualmente o principal país produtor de cana-de-açúcar no mundo, com produção de cerca de 460 milhões de t em $2006{ }^{6}$ Durante a moagem da cana-de-açúcar para a extração do caldo, há geração de bagaço. Esse subproduto é normalmente queimado como combustível em caldeiras que geram o vapor d'água utilizado na produção de açúcar e álcool e em processos de co-geração de energia. A cinza do bagaço é gerada como subproduto. A quantidade de cinza residual produzida anualmente no Brasil equivale a aproximadamente 2,5 milhões de $\mathrm{t},{ }^{4,7}$ valor que representa cerca de $7 \%$ da produção de cimento Portland no Brasil em 2006. ${ }^{8}$ É importante destacar que a queima do bagaço produz substancial liberação de $\mathrm{CO}_{2}$. Entretanto, o balanço nas emissões de $\mathrm{CO}_{2}$ é praticamente nulo, pois, através da fotossíntese, a biomassa queimada é reposta no ciclo seguinte da cultura da cana-de-açúcar. ${ }^{4}$

Este trabalho apresenta a caracterização de uma amostra selecionada de cinza do bagaço, produzida sob condições de queima controladas em laboratório, com base em ensaios de fluorescência de raios X, difração de raios X, ressonância magnética nuclear $\left({ }^{29} \mathrm{Si}\right)$, microscopia eletrônica de varredura, análises térmicas, granulometria 
a laser, superfície específica, massa específica e atividade pozolânica (índice de atividade pozolânica com cimento Portland e método de Chapelle modificado). Para seleção da cinza com características físico-químicas mais adequadas ao emprego como pozolana, foram realizadas queimas com dois patamares e temperaturas entre 400 e 900 ${ }^{\circ} \mathrm{C}$. As variáveis investigadas para a escolha da pozolana foram perda ao fogo e índice de atividade pozolânica. Todas as características analisadas visam a adequação da cinza do bagaço de cana-de-açúcar ao emprego em concretos, argamassas e pastas. Além disso, entende-se que o conhecimento das características de uma cinza produzida sob condições de queima estritamente controladas é importante para a comparação com cinzas residuais produzidas em caldeiras de indústrias sucro-alcooleiras em todo o Brasil.

\section{PARTE EXPERIMENTAL}

O bagaço utilizado como matéria-prima foi proveniente de uma usina de beneficiamento de cana-de-açúcar localizada no município de São João da Barra, Rio de Janeiro, Brasil. A coleta foi efetuada após as operações de lavagem da cana-de-açúcar e moagem para extração do caldo. Em laboratório, a amostra foi lavada com água destilada e submetida à secagem em estufa a $80{ }^{\circ} \mathrm{C}$ por $48 \mathrm{~h}$. Em seguida, o bagaço foi submetido à queima em forno resistivo (mufla) sem circulação forçada de ar. As condições de queima adotadas foram queima com dois patamares; temperatura de $350{ }^{\circ} \mathrm{C}$ no $1^{\circ}$ patamar; temperatura entre 400 e $900{ }^{\circ} \mathrm{C}$ no $2^{\circ}$ patamar, com variação de 100 ${ }^{\circ} \mathrm{C}$; taxa de aquecimento de $10{ }^{\circ} \mathrm{C} / \mathrm{min}$; e tempo de residência em cada patamar de $3 \mathrm{~h}$. A relação entre os volumes de amostra e da câmara interna do forno foi mantida constante em 0,036 para todas as queimas. A opção pelo método de queima com dois patamares, com temperatura de $350{ }^{\circ} \mathrm{C}$ no primeiro patamar, foi feita com base nos estudos sobre produção de cinza da casca de arroz com elevada atividade pozolânica desenvolvidos por Sugita. ${ }^{9}$ Apesar da diferença na composição química entre a cinza do bagaço e a cinza da casca de arroz, o método de queima com dois patamares apresenta similar eficiência na redução da perda ao fogo com menor consumo energético, em comparação com a queima com um patamar e mesmo tempo de queima. ${ }^{4}$

Após a queima, todas as amostras foram submetidas à cominuição a seco em moinho de bolas planetário Restch PM-4 com operação a $300 \mathrm{rpm}$, jarro e corpos moedores (esferas de $10 \mathrm{~mm}$ de diâmetro) de ágata, grau de enchimento de $25 \%$, preenchimento de vazios de $66 \%$ e tempo de moagem de 2 min. Na confecção das argamassas utilizadas para avaliação da atividade pozolânica da cinza foram empregados cimento Portland sem adição mineral e areia de rio normalizada proveniente do Instituto de Pesquisas Tecnológicas do Estado de São Paulo (NBR 7214/1983). ${ }^{10}$ A Tabela 1 apresenta a composição química, em termos de óxidos, a composição potencial de Bogue e as principais características físicas do cimento. A curva granulométrica do cimento é apresentada na Figura 1.

A distribuição de tamanho das cinzas foi obtida via analisador de partículas a laser Mastersizer 2000, Malvern Instruments. As amostras foram dispersas em álcool etílico P.A. e mantidas sob agitação (1700 rpm) por $60 \mathrm{~min}$ no equipamento. A perda ao fogo foi determinada de acordo com os procedimentos prescritos na norma brasileira NBR 5743/1989. ${ }^{11}$ A atividade pozolânica foi determinada por duas metodologias distintas: índice de atividade pozolânica com cimento Portland, baseado na resistência à compressão de argamassas, e Chapelle modificado, ${ }^{12}$ baseado na fixação de $\mathrm{CaO}$ pela cinza. No primeiro método, prescrito na norma brasileira NBR 5752/1992, ${ }^{13}$ o índice de atividade pozolânica foi calculado pela relação entre as resistências médias à compressão, aos 28 dias, de cilindros $(50 \mathrm{~mm}$ de diâmetro e $100 \mathrm{~mm}$ de altura) de argamassa com cinza e argamassa composta apenas por cimento, areia e água (referência). Relações mássicas entre areia-cimento e água-cimento equivalentes a 3,00 e 0,52 , respectivamente, foram empregadas em ambas as argamassas. Nas misturas com as cinzas do bagaço, $35 \%$ do volume absoluto de cimento foram substituídos por cada uma das cinzas avaliadas. Após mistura e moldagem em cilindros metálicos, os corpos-deprova foram mantidos em câmara úmida (temperatura de $21 \pm 1^{\circ} \mathrm{C}$ e umidade relativa de $100 \%$ ) durante as primeiras $24 \mathrm{~h}$. Em seguida, os corpos-de-prova foram desmoldados, selados com filme plástico e mantidos em recipientes hermeticamente fechados à temperatura de $38 \pm 2{ }^{\circ} \mathrm{C}$ até a idade de 28 dias. Ao final do período de cura das argamassas, os corpos-de-prova (4 por mistura) foram submetidos à ruptura em prensa servo-controlada Shimadzu UH-F1000kNI com velocidade de ensaio de $0,1 \mathrm{~mm} / \mathrm{min}$. No segundo método de avaliação adotado, utilizado apenas na caracterização da cinza com

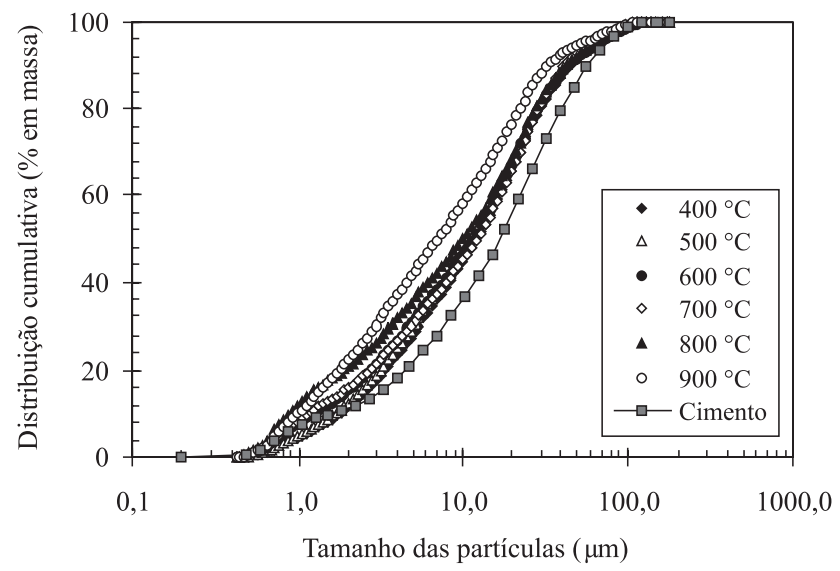

Figura 1. Curvas granulométricas do cimento Portland e das cinzas do bagaço produzidas em diferentes condições de queima

Tabela 1. Características físico-químicas do cimento Portland

\begin{tabular}{lclc}
\hline Composto & Teor (\% em massa) & Fase & Teor (\% em massa) \\
\hline $\mathrm{SiO}_{2}$ & 20,85 & $\mathrm{C}_{3} \mathrm{~S}$ & 64,08 \\
$\mathrm{Al}_{2} \mathrm{O}_{3}$ & 4,23 & $\mathrm{C}_{2} \mathrm{~S}$ & 11,43 \\
$\mathrm{Fe}_{2} \mathrm{O}_{3}$ & 5,25 & $\mathrm{C}_{3} \mathrm{~A}$ & 2,33 \\
$\mathrm{CaO}$ & 63,49 & $\mathrm{C}_{4} \mathrm{AF}$ & 15,98 \\
$\mathrm{Na}_{2} \mathrm{O}$ & 0,16 & Característica (unidade) & Valor \\
$\mathrm{K}_{2} \mathrm{O}$ & 0,40 & Massa específica $\left(\mathrm{kg} / \mathrm{m}^{3}\right)$ & 3170 \\
$\mathrm{SO}_{3}$ & 2,38 & Superfície específica, Blaine $\left(\mathrm{m}^{2} / \mathrm{kg}\right)$ & 308 \\
Perda ao fogo & 1,05 & Resíduo, peneira 325 mesh $(\%)$ & 8,40 \\
\hline
\end{tabular}


maior índice de atividade pozolânica, a pozolanicidade da cinza foi determinada com base na capacidade do material de fixar hidróxido de cálcio quando mantido em solução aquosa com óxido de cálcio. De forma simplificada, o método de Chapelle modificado consiste em manter em aquecimento $\left(90^{\circ} \mathrm{C}\right)$ sob agitação, durante $16 \mathrm{~h}$, uma solução com 1,000 g de óxido de cálcio, 1,000 g de cinza e 250,0 g de água isenta de dióxido de carbono. ${ }^{12}$ Ao final do ensaio, o teor de $\mathrm{CaO}$ livre é medido, por meio de titulação de cerca de $50 \mathrm{~mL}$ da solução com $\mathrm{HCl}$ 0,1 N e fenolftaleína (1 g/L), e estima-se a quantidade de $\mathrm{CaO}$ que foi combinada com a pozolana. O resultado é expresso pela quantidade de óxido de cálcio fixado por grama de cinza.

A análise de difração de raios $\mathrm{X}$, pelo método do pó, foi realizada em difratômetro Rigaku Miniflex com tubo de $\mathrm{Cu}-\mathrm{K} \alpha(30 \mathrm{kV} / 15 \mathrm{~mA})$, com coleta entre $5^{\circ}$ e $50^{\circ}(2 \theta)$, velocidade do goniômetro de $0,05^{\circ}$ / passo e tempo de contagem de $2 \mathrm{~s}$ por passo. A interpretação qualitativa foi efetuada por comparação com padrões do banco de dados $P D F-2^{14}$ do International Center for Diffraction Data. A composição química foi determinada por fluorescência de raios X (espectrômetro Phillips PW 2400) com tubo de $3 \mathrm{~kW}$ e alvo de ródio. A amostra foi seca em estufa por $48 \mathrm{~h}$ a $60{ }^{\circ} \mathrm{C}$ e prensada com ácido bórico para formação de disco. A análise por ressonância magnética nuclear $\left.{ }^{29} \mathrm{Si}\right)$ foi realizada em espectrômetro Infinity Plus-400 com as seguintes condições experimentais: frequiência de 79,4 MHz, rotor de zircônio (7,5 mm), rotação de $5 \mathrm{~Hz}$, duração do pulso $(\pi / 2)$ de $5 \mu \mathrm{m}$, intervalo de $30 \mathrm{~s}$ e número de transientes de 500. A superfície específica da amostra foi obtida por adsorção de nitrogênio (método BET) em equipamento Gemini 2375 V5. A massa específica foi determinada em picnômetro a gás (He), modelo Accupyc, da Micromeritics. A caracterização morfológica foi efetuada por microscopia eletrônica de varredura em microscópio Jeol JXA 840-A com detecção de imagens a partir de elétrons secundários. Os ensaios térmicos (análise térmica diferencial e termogravimetria) foram realizados em módulo simultâneo SDT Q600 da TA Instruments. Utilizou-se cadinho de 90 $\mu \mathrm{L}$ de alumina, massa de amostra de $10 \mathrm{mg}$, razão de aquecimento de $10^{\circ} \mathrm{C} / \mathrm{min}$, desde a temperatura ambiente até $950^{\circ} \mathrm{C}$ e vazão máxima de ar de $100 \mathrm{~mL} / \mathrm{min}$.

\section{RESULTADOS E DISCUSSÃO}

\section{Determinação da temperatura ideal de queima}

As moagens foram realizadas no intuito de equiparar a granulometria das cinzas produzidas sob diferentes temperaturas, como pode ser observado na Figura 1. Esse procedimento é importante tendo em vista que a atividade pozolânica varia com o tamanho das partículas do material. Os diferentes produtos de moagem apresentam granulometria não uniforme e tamanho médio de partículas entre 7 e $12 \mu \mathrm{m}$. As cinzas apresentam cerca de $70 \%$ das partículas compreendidas entre 3 e $30 \mu \mathrm{m}$, faixa típica de tamanho de partículas de grande parte dos cimentos Portland produzidos no Brasil. ${ }^{15}$

Os resultados de perda ao fogo são apresentados na Figura 2. $\mathrm{O}$ método de queima adotado revela-se muito adequado para a remoção de carbono e compostos voláteis presentes na cinza. Como esperado, a perda ao fogo diminui significativamente à medida que a temperatura de queima aumenta. De acordo com Malhotra e Mehta, ${ }^{16}$ uma cinza pozolânica deve apresentar perda ao fogo máxima de $6 \%$, mesmo valor apontado na NBR 12653/1992, ${ }^{17}$ norma que estabelece os critérios de classificação de pozolanas no Brasil. Com isso, para as condições empregadas, a temperatura de queima deve ser igual ou superior a $600{ }^{\circ} \mathrm{C}$, temperatura na qual a cinza do bagaço apresenta valor de perda ao fogo igual a $5,7 \%$.

A Tabela 2 apresenta os valores de índice de atividade pozolânica, calculados a partir da resistência à compressão de referência de 37,81

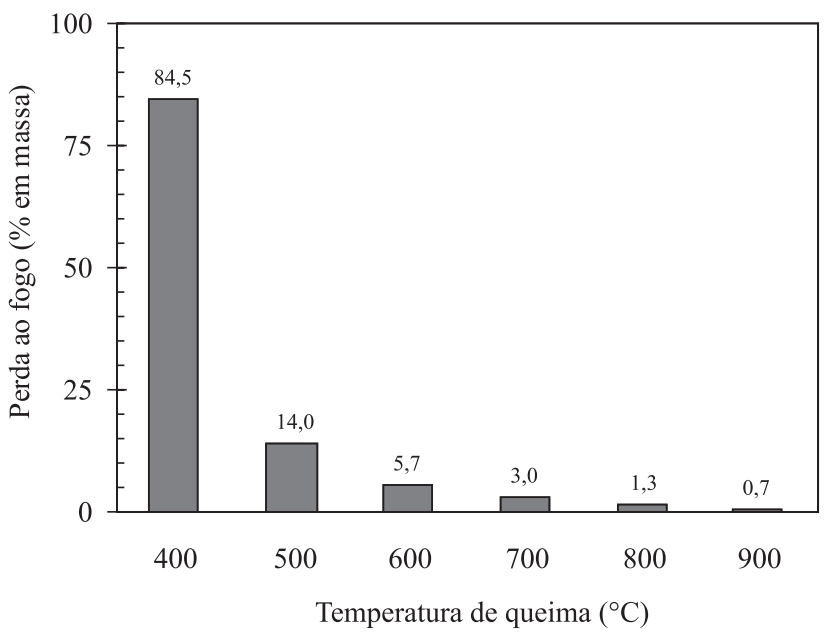

Figura 2. Valores de perda ao fogo das cinzas do bagaço produzidas em diferentes condições de queima

Tabela 2. Valores de índice de atividade pozolânica com cimento Portland (NBR 5752/1992) ${ }^{13}$ das diferentes cinzas do bagaço

\begin{tabular}{lc}
\hline Temperatura de queima $\left({ }^{\circ} \mathrm{C}\right)$ & Índice de atividade pozolânica $(\%)$ \\
\hline 400 & 28 \\
500 & 73 \\
600 & 77 \\
700 & 63 \\
800 & 69 \\
900 & 73 \\
\hline
\end{tabular}

MPa. É possível observar que há variação da atividade pozolânica da cinza em função da temperatura de queima. Entretanto, não existe uma tendência definida entre os dois parâmetros (atividade e temperatura). Com exceção da cinza produzida a $600{ }^{\circ} \mathrm{C}$, que apresenta índice de atividade igual a 77\%, as demais amostras não alcançam o valor mínimo $(75 \%)$ estipulado pela NBR $12653 / 1992{ }^{17}$ para que um material possa ser classificado como pozolana. A reduzida reatividade da cinza produzida a $400{ }^{\circ} \mathrm{C}$ pode ser atribuída à diluição das fases ativas, em razão do elevado teor de carbono presente na amostra (84,5\%). De acordo com as variáveis investigadas, a temperatura de queima de 600 ${ }^{\circ} \mathrm{C}$ é a mais apropriada, dentre as temperaturas e demais condições de queima estudadas, para a produção de uma cinza pozolânica do bagaço de cana-de-açúcar.

\section{Caracterização da cinza selecionada}

A composição química da amostra de cinza do bagaço selecionada (produzida a $600{ }^{\circ} \mathrm{C}$ ), conforme apresentado no subitem anterior, pode ser observada na Tabela 3 . O $\mathrm{SiO}_{2}$ é o composto predominante da cinza, com $60,96 \%$ da massa de amostra. Os óxidos $\mathrm{K}_{2} \mathrm{O}, \mathrm{MgO}$, $\mathrm{P}_{2} \mathrm{O}_{5}$ e $\mathrm{CaO}$ representam cerca de $32 \%$ da cinza. Impurezas também são encontradas na forma de $\mathrm{Na}_{2} \mathrm{O}, \mathrm{MnO}, \mathrm{Al}_{2} \mathrm{O}_{3}$ e $\mathrm{Fe}_{2} \mathrm{O}_{3}$, com teores inferiores a $1 \%$. Cabe ressaltar que a composição química da cinza do bagaço pode variar em função do tipo de cana-de-açúcar cultivada, fertilizantes e herbicidas, além de fatores naturais, tais como clima, solo e água.

O difratograma de raios X da amostra, Figura 3, não apresenta evidências de sílica em estado cristalino, pela ausência de picos de quartzo, cristobalita e tridimita. A banda larga entre $20^{\circ}$ e $30^{\circ}(2 \theta)$ pode ser 
Tabela 3. Composição química, em termos de óxidos, da cinza do bagaço produzida a $600{ }^{\circ} \mathrm{C}$

\begin{tabular}{lc}
\hline Composto & Teor (\% em massa) \\
\hline $\mathrm{SiO}_{2}$ & 60,96 \\
$\mathrm{Al}_{2} \mathrm{O}_{3}$ & 0,09 \\
$\mathrm{Fe}_{2} \mathrm{O}_{3}$ & 0,09 \\
$\mathrm{CaO}$ & 5,97 \\
$\mathrm{Na}_{2} \mathrm{O}$ & 0,70 \\
$\mathrm{~K}_{2} \mathrm{O}$ & 9,02 \\
$\mathrm{MnO}$ & 0,48 \\
$\mathrm{MgO}$ & 8,65 \\
$\mathrm{P}_{2} \mathrm{O}_{5}$ & 8,34 \\
$\mathrm{Perda}$ ao fogo & 5,70 \\
\hline
\end{tabular}

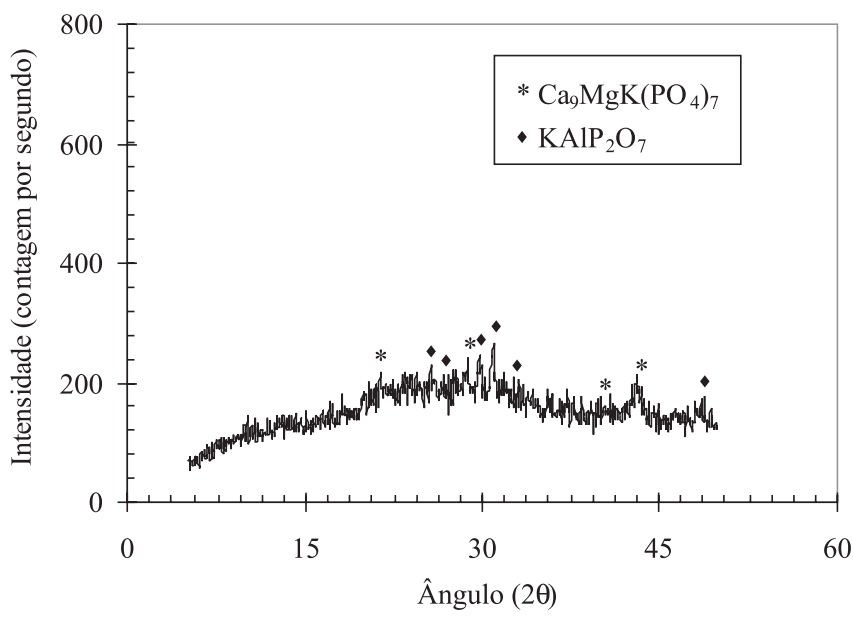

Figura 3. Difratograma de raios X da cinza do bagaço produzida a $600{ }^{\circ} \mathrm{C}$

atribuída à existência de sílica amorfa, que confere atividade pozolânica à cinza. São observadas fases cristalinas referentes ao fosfato de cálcio, magnésio e potássio $\left[\mathrm{Ca}_{9} \mathrm{MgK}\left(\mathrm{PO}_{4}\right)_{7}\right]$ e ao pirofosfato de alumínio e potássio $\left(\mathrm{KAlP}_{2} \mathrm{O}_{7}\right)$, coerentes com a composição química da cinza apresentada na Tabela 3. A análise da cinza por ressonância magnética nuclear de ${ }^{29} \mathrm{Si}$ (Figura 4a) corrobora com o resultado da difração de raios X. Neste caso, o espectro de ressonância revela a predominância da sílica em grupamentos do tipo $\mathrm{Q}^{4}(-110 \mathrm{ppm})$, indicativo da sílica em estado amorfo, ${ }^{18}$ conforme a Figura $4 \mathrm{~b}$.

Com relação à caracterização micro-morfológica, a cinza produzida a $600{ }^{\circ} \mathrm{C}$ apresenta partículas com tamanhos e formas variados, como indica a Figura 5. Constata-se a presença de partículas prismáticas, com arestas bem definidas em contraste com partículas de estrutura celular e alta porosidade. A elevada porosidade da cinza é consequiência da liberação da matéria orgânica durante a queima do bagaço. A Figura 6 apresenta os resultados da análise térmica da cinza do bagaço. A curva de análise térmica diferencial revela um amplo pico exotérmico com valor máximo na temperatura de 228 ${ }^{\circ} \mathrm{C}$, indicativo da eliminação de substâncias voláteis e combustão de carbono remanescentes da queima do bagaço em forno mufla. $\mathrm{O}$ processo de combustão da cinza do bagaço é extremamente complexo pelo grande número de reações simultâneas e pela difusão de substâncias voláteis. ${ }^{19} \mathrm{~A}$ perda de massa total até $950{ }^{\circ} \mathrm{C}$, obtida pela curva termogravimétrica, é igual a $6,23 \%$ e está de acordo com o resultado do ensaio de perda ao fogo (Figura 2 e Tabela 3 ).

A Tabela 4 apresenta importantes características físicas da cinza (a)

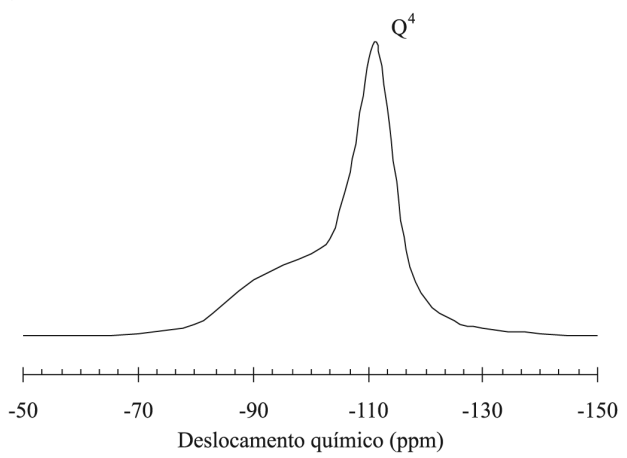

(b)

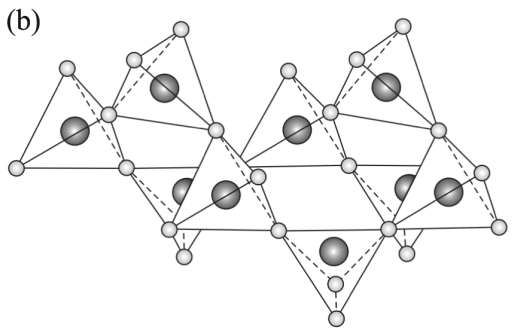

Oxigênio

Silício

Figura 4. Espectro de ressonância magnética nuclear $\left({ }^{29} \mathrm{Si}\right)$ da cinza do bagaço produzida a $600{ }^{\circ} \mathrm{C}($ a). Representação esquemática dos tetraedros de $\mathrm{SiO}_{4}^{-4}(b)$

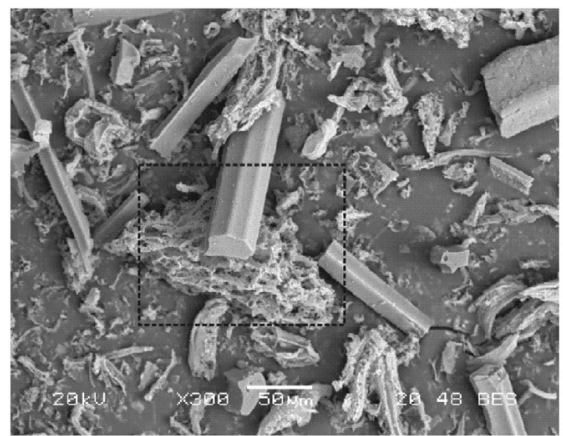

(a)

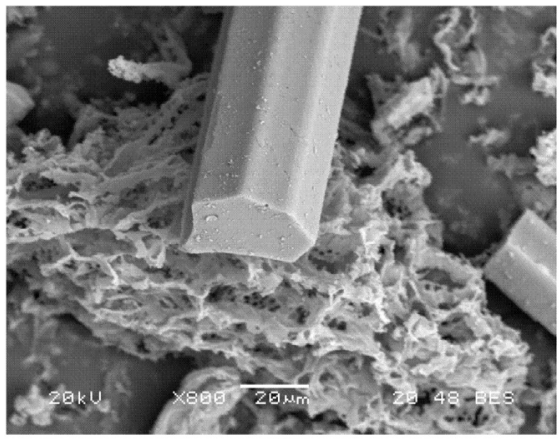

(b)

Figura 5. Detalhes morfológicos da cinza do bagaço produzida a $600{ }^{\circ} \mathrm{C}$ (a). Em detalhe (b), a presença de partículas prismáticas e com estrutura celular de alta porosidade

do bagaço. A amostra apresenta, para as condições de cominuição adotadas, 8,27\% da massa retida na peneira de 325 mesh $(45 \mu \mathrm{m})$, valor próximo ao do cimento utilizado no estudo (Tabela 1). A cinza apresenta cor cinza, umidade residual reduzida e valor massa espe- 


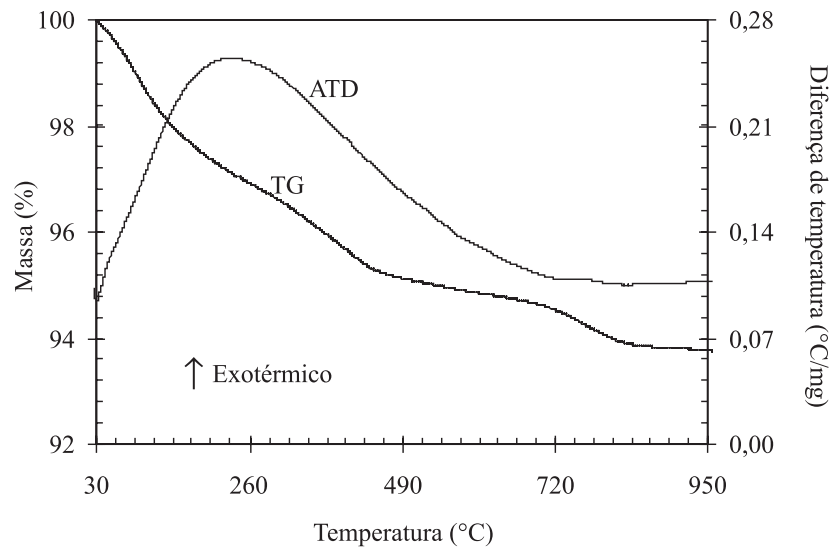

Figura 6. Análises térmica diferencial (ATD) e termogravimétrica $(T G)$ da cinza do bagaço produzida a $600{ }^{\circ} \mathrm{C}$

Tabela 4. Características físicas da cinza do bagaço produzida com queima a $600{ }^{\circ} \mathrm{C}$

\begin{tabular}{lc}
\hline Característica (unidade) & Valor \\
\hline Umidade $(\%)$ & 2,1 \\
Massa específica $\left(\mathrm{kg} / \mathrm{m}^{3}\right)$ & 2569 \\
Superfície específica, BET $\left(\mathrm{m}^{2} / \mathrm{kg}\right)$ & 11887 \\
Cor em $600{ }^{\circ} \mathrm{C}$ & Cinza \\
Resíduo, peneira 325 mesh $(\%)$ & 8,27 \\
\hline
\end{tabular}

cífica dentro da faixa esperada para materiais silicosos. ${ }^{20} \mathrm{O}$ valor apresentado para a superfície específica (BET) da cinza é característico para cinzas de origem celular e com elevado teor de sílica amorfa. ${ }^{4,20}$ Como as reações pozolânicas iniciam-se pela superfície das partículas, a elevada superfície específica é um importante parâmetro de qualidade da cinza do bagaço.

No tocante à atividade pozolânica avaliada pelo método de Chapelle modificado, a cinza do bagaço de cana-de-açúcar apresenta valor de fixação igual a $421 \mathrm{mg} / \mathrm{g}$ (mg de $\mathrm{CaO}$ por g de cinza). Esse valor de atividade é expressivamente superior (28\%) ao valor mínimo atribuído a materiais pozolânicos $(330 \mathrm{mg} / \mathrm{g})$ por Raverdy et al.. ${ }^{12}$ Os resultados obtidos nas duas metodologias de avaliação adotadas, baseadas em ensaios de resistência à compressão de argamassas e químicos, confirmam o potencial da cinza do bagaço para emprego como pozolana. Este comportamento está de acordo com pesquisas desenvolvidas com cinzas do bagaço produzidas sem controle das condições de queima ${ }^{21-23}$ e com queima controlada em laboratório., ${ }^{419}$

\section{CONCLUSÕES}

Com base nos resultados, é possível concluir que a cinza do bagaço de cana-de-açúcar se apresenta como matéria-prima com potencial para a produção de pozolana. Especificamente, a cinza produzida com queima controlada a $600{ }^{\circ} \mathrm{C}$ em forno resistivo, e cominuída em moinho planetário, apresenta atividade pozolânica adequada com vistas aos requisitos propostos na NBR 12653/1992.
A elevada atividade pozolânica da cinza do bagaço pode ser atribuída à presença de sílica amorfa, ao reduzido tamanho de partículas, à elevada superfície específica e à reduzida perda ao fogo.

\section{AGRADECIMENTOS}

À Companhia Açucareira Usina Barcelos pelo fornecimento da cinza do bagaço e às agências Faperj, Capes e CNPq pelo auxílio financeiro.

\section{REFERÊNCIAS}

1. Massazza, F. Em Lea's Chemistry of Cement and Concrete; Hewlett, P. C., ed.; $4^{\text {th }}$ ed., J. Wiley: New York, 1988, cap. 10.

2. ACI American Concrete Institute; Cementitious Materials for Concrete - ACI Education Bulletin E3-01, 2001.

3. Taylor, H. F. W.; Cement Chemistry, $2^{\text {nd }}$ ed., Thomas Telford: London, 1997.

4. Cordeiro, G. C.; Tese de Doutorado, Universidade Federal do Rio de Janeiro, Brasil, 2006.

5. Barboza Filho; M. P.; Prabhu, A. S.; Aplicação de Silicato de Cálcio na Cultura de Arroz, Embrapa: Santo Antônio de Goiás, 2002.

6. http://www.fao.org, acessada em Dezembro 2007.

7. http://www.ibge.net/home/estatistica, acessada em Novembro 2007.

8. http://www.snic.org.br/f_numeros.html, acessada em Abril 2007.

9. Sugita, S.; $3^{\text {rd }}$ International Conference on the Concrete Future, Kuala Lumpur, Malaysia, 1994.

10. Associação Brasileira de Normas Técnicas; Areia Normal para ensaio de cimento, NBR 7214, Rio de Janeiro, 1982.

11. Associação Brasileira de Normas Técnicas; Cimento Portland Determinação da perda ao fogo, NBR 5743, Rio de Janeiro, 1989.

12. Raverdy, M.; Brivot, F.; Paillère, A. M.; Bron, R.; 7 Congrés Internatinal de la Chimie des Ciments, Paris, France, 1980.

13. Associação Brasileira de Normas Técnicas; Materiais pozolânicos Determinação da atividade pozolânica com cimento Portland - Índice de atividade pozolânica com cimento, NBR 5752, Rio de Janeiro, 1992.

14. PDF-2; Powder Diffraction File - Version 2.074, International Centre for Diffraction Data, Pennsylvania, 2007.

15. Kihara, Y.; Centurione, S. L. Em Concreto: Ensino, Pesquisa e Realizações; Isaia, G. C., ed.; $1^{\text {a }}$ ed., Ibracon: São Paulo, 2005, cap. 10.

16. Malhotra, V. M.; Mehta, P. K.; Pozzolanic and Cementitious Materials, $1^{\text {st }}$ ed., Gordon and Breach Publishers: Amsterdam, 1996.

17. Associação Brasileira de Normas Técnicas; Materiais pozolânicos, NBR 12653, Rio de Janeiro, 1992.

18. Zanni, H.; Cheyrezy, M.; Maret, V.; Philippot, S.; Nieto, P.; Cem. Concr. Res. 1996, 26, 93.

19. Roque-Diaz, P.; Shemet, V. Z.; Lavrenko, V. A.; Khristich, V. A.; Thermochim. Acta 1985, 93, 349.

20. Della, V. P.; Khun, I.; Hotza, D.; Quim. Nova 2001, 24, 778.

21. Martirena Hernández, J. F. M.; Middeendorf, B.; Gehrke, M.; Budelmann; Cem. Concr. Res. 1998, 23, 1525.

22. Payá, J.; Monzó, J.; Borrachero, M. V.; Díaz-Pinzón, L.; Ordónez, L. M.; J. Chem. Technol. Biotechnol. 2002, 77, 321.

23. Cordeiro, G. C.; Toledo Filho, R. D.; Tavares, L. M.; Fairbairn, E. M. R.; Cem. Concr. Compos. 2008, 30, 410. 